\title{
What makes a good clinical student and teacher? An exploratory study
}

John Goldie ${ }^{1,5^{*}}$, Al Dowie', Anne Goldie ${ }^{2}$, Phil Cotton ${ }^{1,3}$ and Jill Morrison ${ }^{4}$

\begin{abstract}
Background: What makes a good clinical student is an area that has received little coverage in the literature and much of the available literature is based on essays and surveys. It is particularly relevant as recent curricular innovations have resulted in greater student autonomy. We also wished to look in depth at what makes a good clinical teacher.

Methods: A qualitative approach using individual interviews with educational supervisors and focus groups with senior clinical students was used. Data was analysed using a "framework" technique.

Results: Good clinical students were viewed as enthusiastic and motivated. They were considered to be proactive and were noted to be visible in the wards. They are confident, knowledgeable, able to prioritise information, flexible and competent in basic clinical skills by the time of graduation. They are fluent in medical terminology while retaining the ability to communicate effectively and are genuine when interacting with patients. They do not let exam pressure interfere with their performance during their attachments.

Good clinical teachers are effective role models. The importance of teachers' non-cognitive characteristics such as inter-personal skills and relationship building was particularly emphasised. To be effective, teachers need to take into account individual differences among students, and the communicative nature of the learning process through which students learn and develop. Good teachers were noted to promote student participation in ward communities of practice. Other members of clinical communities of practice can be effective teachers, mentors and role models.

Conclusions: Good clinical students are proactive in their learning; an important quality where students are expected to be active in managing their own learning. Good clinical students share similar characteristics with good clinical teachers. A teacher's enthusiasm and non-cognitive abilities are as important as their cognitive abilities. Student learning in clinical settings is a collective responsibility. Our findings could be used in tutor training and for formative assessment of both clinical students and teachers. This may promote early recognition and intervention when problems arise.
\end{abstract}

Keywords: Good clinical student, Good clinical teacher, Undergraduate medical education

\section{Background}

What makes a good clinical student is an area that has received little coverage in the literature [1]. It is particularly relevant as recent curricular innovations have resulted in greater student autonomy in managing their own learning [2]. Glasgow University's medical curriculum has undergone such curricular change with the introduction of a learner-centred, problem-based curriculum and the embracing of an outcome-based approach to learning [3]. As part of a larger research study,

\footnotetext{
* Correspondence: John.Goldie@glasgow.ac.uk

'Glasgow University Medical School, Glasgow, Scotland, UK

${ }^{5}$ Academic Unit of General Practice and Primary Care, University of Glasgow,

1 Horselethill Road, Glasgow G12 9LX, Scotland, UK

Full list of author information is available at the end of the article
}

looking at how students form their professional identities, we were interested in our students' and tutors' views on what makes a good clinical student.

Teaching and mentoring medical students and junior doctors is considered "Good Medical Practice" [4]. Doctors who undertake teaching and supervision should also develop the skills, attitudes and practices of a competent teacher [4]. Recent literature reviews [5-7] have identified a degree of consensus on what characterises a good medical teacher:

Clinical knowledge, clinical and technical competence, positive relationships with students, effective communication skills, enthusiasm.

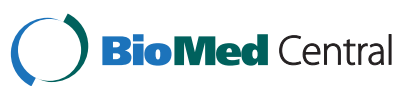

(C) 2015 Goldie et al.; licensee BioMed Central. This is an Open Access article distributed under the terms of the Creative Commons Attribution License (http://creativecommons.org/licenses/by/4.0), which permits unrestricted use, distribution, and reproduction in any medium, provided the original work is properly credited. The Creative Commons Public Domain Dedication waiver (http://creativecommons.org/publicdomain/zero/1.0/) applies to the data made available in this article, unless otherwise stated. 
Many of the papers identified, however, were essays or surveys of students, residents or colleagues [5]. We also wished to explore in more depth students' and tutors' perspective on what makes a good clinical teacher.

We hoped the findings would inform and promote reflection by Medical School staff, management and students, and contribute to the wider literature.

\section{Methods}

We decided to use individual interviews with educational supervisors, clinical teachers responsible for mentoring students and overseeing their clinical education, and focus groups with senior students from years $4 / 5$ (a two-year clinical rotation). It was felt that the use of focus groups would promote a feeling of safety, encourage participation and help generate more realistic accounts of what students' think [8]. This had to be balanced against the likelihood of eliciting conventional or conforming group-think, which was felt less likely as the group was homogenous with no obvious power differentials among members.

\section{Ethical approval}

Ethical consent for the study was obtained from the College of Medical, Veterinary and Life Sciences Ethics committee and the Greater Glasgow and Clyde National Health Service Local Research Ethics Committee.

\section{Participants}

A purposive sample of ten educational supervisors, stratified in terms of the range of specialties involved in teaching and whether the supervisor worked in a Glasgow teaching hospital or in the 19 West of Scotland hospitals that deliver 30\% of clinical teaching at Glasgow University, was proposed. Hospital sub-deans were approached to help identify suitable participants. Unfortunately due to a poor initial response the researchers also made individual contact with potential participants. Our participant group worked in a range of specialties and settings (Table 1). Informed consent was obtained from each supervisor.

\begin{tabular}{|c|c|}
\hline \multirow[t]{2}{*}{ Gender } & 8 Male \\
\hline & 2 Female \\
\hline Hospital & 6 Glasgow Teaching Hospitals \\
\hline \multirow[t]{2}{*}{ Base } & 3 District General Hospitals \\
\hline & 1 Psychiatric Hospital \\
\hline \multirow[t]{3}{*}{ Specialty } & 7 Medical specialties \\
\hline & 2 Surgical \\
\hline & 1 Psychiatry \\
\hline
\end{tabular}

Three focus groups were to be run with purposive samples of year $4 / 5$ students. Due to poor student response a convenience sample of three groups of 5 to 6 students participated. They were representative of year $4 / 5$ students in Glasgow in terms of age, gender and holding previous and intercalated degrees. Informed consent was obtained prior to participation.

The interviews were conducted by AG a researcher external to the Medical School whose background is in nursing and counselling research. The interviews were semi-structured. AG and $\mathrm{AD}$, our qualitative researcher, met on a number of occasions prior to the interviews to produce a broad topic guide of the issues to be covered based on the aims of the study. A conversational style was adopted with participants encouraged to respond freely. The topic guide was refined following reflection on the initial interviews.

The first and third focus groups were conducted by JG a researcher in the School of Medicine who had no previous contact with any of the participants. The second was conducted by PC, who was Associate Dean for Student Welfare at the time. The broad topic guide was again used. Prior to the groups taking place, the moderators met with AD and AG to help maximise uniformity of the moderator approach, which was to keep intervention to a minimum. However, the moderators were encouraged to play devil's advocate where necessary if there was a perceived threat of group think.

\section{Analysis}

The interviews and focus groups were audio-taped and transcribed. Although review of the transcripts and discussion of themes was ongoing, the main process of analysis was carried out when data collection was completed. A "framework" technique developed by the National Centre for Social Research was used [9]. This was considered an appropriate approach in a study where some of the research questions were predetermined and which was geared towards generating practice-orientated findings. Analysis was performed by JG. The first step involved familiarisation with the data. The next steps involved thematic analysis to develop a coding scheme. The data was then indexed and charted with comparison both within and across the interviews. Discomforting data was examined, for example one supervisor had not witnessed much interaction between students and health care professionals. Given the position of the moderator, PC, the dynamic of his focus group was examined to determine if it had been adversely affected. No discernible difference was found in the content generated in this focus group compared with the other two. There were only a few occasions where the moderators played devil's advocate. In mapping and interpreting the data, locating the empirical findings 
from within the wider literature on professionalism, social learning and identity, helped make sense of the data.

The last two interviews and the third focus group generated no new data. Data saturation was considered to have been reached.

The analytical process and findings were reviewed throughout by AD, AG and PC.

\section{Results}

The themes identified by the interviews and focus groups are shown in Table 2. The numerical counts are intended to convey a sense of the distribution of themes across interviews and focus groups.

\section{What makes a good clinical student}

Students considered to be good, proactively participate taking every opportunity to learn. They are considered knowledgeable, mature, confident, team players who are able to take to criticism. Poor students, in contrast, attend less frequently and when they do, tend not to participate to the same extent. They appear to supervisors as anxious and scared of patients' illnesses and seem afraid of taking responsibility.

"(Good students) they will come and ask for computer passwords to get access to results to help on the ward round tomorrow. That would give me a signal that they're keen to learn and get experience of what real life work is. They are trying to be helpful and (contribute) to the team...they stay behind at night and give the resident a hand...their case histories (are more insightful)".

\section{(Supervisor interview A)}

"(A good student) is intelligent, but it is on display, they're interested, ask questions, they want to know things...that stimulates me (in turn) and I get right into it...A bad student is the one who turns up late, or not at all, they give the impression they're only there to tick the box. I mean the good student engages with you (has good eye contact) verses the (bad student) who stares at the ceiling or looks at the floor and you're lucky if you get three syllables out of them".

\section{(Supervisor interview J)}

"The best ones have good background knowledge and are able to prioritise it and apply it quickly...they grasp the important things quickly...(Poor students) haven't put the time in to (acquire) the same knowledge...they can't prioritise the important bits of information from the less important, for example picking out the relevant bits from the history and bringing it together in a diagnostic solution....(The best students) also approach patients like fellow human beings...they can relate to patients and laugh with them".

\section{(Supervisor interview I)}

"(Poor students) turn up late and clock off early. If they can't manage (for example) to site a venflon and its getting near when they finish they don't take responsibility and get someone else to do it, they just leave. They have no sense of vocation".

\section{(Supervisor interview B)}

"(Poor students) when asked (during ward teaching) to take a history and examine a patient get very anxious about it. Their a bit scared of them I think because (the patients) are ill and I suppose there's a huge anxiety of thinking in a few years time that (they are) going to (be responsible)".

\section{(Supervisor interview C)}

"(Bad student)...unprepared, lazy, doesn't take the initiative...(Good students) take the initiative, if you do you can have endless learning opportunities...just present yourself with your badge and you can, for example, do pathology for a day...even better if a consultant takes you under their wing. I got one who let me scrub in and I got to assist at lots of operations".

\section{(Student focus group 1)}

"(Good student) needs to be intelligent, dedicated, but at the same time you need to have a perspective on what your learning...self awareness of your competency...Also it's your responsibility (to develop knowledge and skills), you have to put yourself out there, for example find a doctor to show you how to take blood".

\section{(Student focus group 3)}

They are expected, by both their teachers and their peers, to dress conservatively and become fluent in medical terminology while retaining the ability to communicate effectively and be genuine when dealing with patients. They do not let exam pressure interfere with their performance during their attachments.

"Some of them don't know what a hemicolectomy means...they use terms like wound in the tummy... while its important to be (able to communicate effectively with patients)...when students use 
Table 2 Themes identified by interviews and focus groups

\section{Characteristics of a good clinical student}

Teachers

Participates in learning/good attendance - 10

Proactive -5

Enthusiastic - 8

Mature/confident/not afraid to ask for help - 8

Knowledgeable/skills competence - 7

Communication skills - 6

Takes responsibility for learning/independent - 5

Does not let exam pressures interfere with performance on attachment -5

Caring of patients/genuine - 4

Sense of vocation - 3

Team player - 3

Able to recognize position in hierarchy - 1

Should conform to norms of dress -7

Avoid jeans, earings/piercings, bare midrifts/sexualized appearance

\section{Characteristics of a good clinical teacher}

\section{Teachers}

Act as positive role models - 10

Develops relationship with students - 6

Respects students - 5

Cares about students - 4

Promotes students' participation in communities of practice - 6

Makes time to teach -5

Provides one-to-one teaching - 4

Interested and committed to teaching - 5

Provides feedback - 5

Relevant to curricular stage - 2

Should become fluent in language of medicine/bilingual in being able to adjust language when talking to patients -7

\section{Students}

Participates in learning/good attendance - 3

Proactive -3

Enthusiastic - 3

Knowledgeable - 3

Able to take risks in a safe environment - 3

Offer peer support - 3

is promoted by shared experience and seen as an investment in the future

Confident -2

Aware of limitations - 2

Team player - 2

Able to take criticism - 2

Should conform to norms of dress - 3

Students aware of overt pressure to conform to norms of dress - 3

Avoid casual dress, piercings, sexualized appearance - 3

Promotes identification as medical student - 2

Taken more seriously by ward staff -2

Can hide behind clothes/make oneself look older - 2

Can become less conformative as move up hierarchy - 2

Changing clothes is a method of switching off -2

Should become fluent in language of medicine/bilingual in being able to adjust language when talking to patients - 3

\section{Students}

Act as positive role models - all 3 groups

Develops relationships with students - 3

Enthusiastic/appears to enjoy teaching/confident - 3

Knowledgeable/technically competent - 3

Makes time to teach - 3

Provides relevant learning experiences - 2

Promotes students' abilities to take risks in safe environments - 2

Supportive - 3

Encouraging- 3

Treat students with respect - 3

Provide honest constructive feedback - 3

Provides feedback consistent with curricular stage - 2

Genuine with patients, students and colleagues - 3

Good interpersonal skills - 2

Team player - 3

Avoids humiliating students - 3

Has developed teaching skills - 2

Appears to have a true vocation - 2

Ability to listen - 2

Sense of humour - 1

\section{Junior doctors and other Health Care Professionals as role models and mentors}

It is important for students to develop relationships with junior doctors who Junior doctors are able to empathise more with students - 3 can act as role models and mentors - 5

Students identify with junior doctors more easily - 4

Can be more welcoming

It is important for students to develop relationships with other health care professionals - 5 
Table 2 Themes identified by interviews and focus groups (Continued)

\begin{tabular}{ll}
\hline Helps students learn about teamwork & More able to form relationships with students \\
& Other Health Care professionals can be effective teachers and mentors - 2 \\
& Nurses provide mentoring for developing practical skills \\
& Useful source of practical knowledge \\
Important to develop relationships with HCPs to facilitate teaching & Recognition of importance of establishing relationships to facilitate \\
learning & HCP, especially nurse teaching helps boost confidence and makes \\
student feel part of team
\end{tabular}

professional language it must be correct...It allows everyone (in the profession), from Land's end to John O'Groats, from Florida to Alaska, to understand (what you're talking about)".

(Supervisor interview B)

\section{What makes a good clinical teacher}

The importance of the clinical teacher as a positive role model and mentor was emphasised by both students and supervisors:

"He was just himself with (his) patients... he was sitting forward, nodding, doing everything it says in the book, but really empathic. I think when you can do that and your patients like you and respect you then I think you are a doctor rather than someone trying to be a doctor".

(Student focus group 1)

"I had a (teacher) who took me through a chest X-Ray and I don't think I'll ever forget it ...he compared it to looking at a tree...you need to look at all the bits you might forget first like the diaphragm, that's the roots... then the vertebrae, that's the trunk, and then the main branches, that's the ribs... analogies like that, do help".

(Student focus group 3)

"When (students are) shadowing me (it is possible) to model a sense of vocation...if my list has finished early and a colleague's is running late (as an example of teamwork) I'll take cases from him and do them for him so that (the cases) are managed appropriately and (promptly)".

\section{(Supervisor interview A)}

"I had this student who performed badly in her clinical exam ...I took her aside and said 'let's just think about what happened'...inside five minutes she was in tears and we worked through to the fact she had major exam nerves ... and I managed to point her in the direction of psychological help. Later I bumped into her after her (finals) OSCE... she was smiling and did fine".

(Supervisor interview J)

Students could also learn from negative role models

"I think respect's a big thing. I've been on wards where the doctor might be skilled (technically) but doesn't have a good manner with (patients and staff) ...You can tell the nurses don't like them and make jokes about them behind their backs...I want to have the respect of my colleagues as well as be capable of (doing) my job well".

\section{(Student focus group 3)}

Good clinical teachers are considered to be skilled communicators who are knowledgeable, committed, enthusiastic and genuine. They should have good teaching skills. They take time to develop relationships with students and encourage students' participation. They provide honest, constructive feedback relevant to students' curricular stage. They are observed to exhibit the same characteristics during their clinical work:

"I think it's (teachers) who take time with you and treat you as an equal...people with a superior level of knowledge that can impart that to you well...people that seem to relate to patients and other team members very well. Someone you feel you have confidence in and would like them to be your doctor".

(Student focus group 3)

"A bad teacher ...harasses and berates you in front of other members of staff...doesn't give you constructive criticism...in order to learn you have to take risks, to ask questions and to question others and it makes you 
not to want to...You have to instil (students with) confidence, you have to make them feel they're actually able to do it, emulate what's in front of them. When you humiliate students...it's counterproductive they just regress (your) not inspired to go away and learn (from your mistakes). A good teacher...they've been training doctors for ages and pick up my strengths and weaknesses without me saying it and they say 'ok you're quite good at this but let's work on that".

\section{(Student focus group 1)}

Junior doctors can be effective teachers and mentors. They are perceived by students as often being more approachable and empathic. Other health care professionals, particularly nursing staff, could also be effective teachers and mentors. These relationships are promoted by students' proactive participation and the development of interpersonal relationships.

"There was this junior doctor who was really efficient and on top of things (and helped us when asked). What was (just as) important was she always had a big smile for everybody, even when things were getting stressful she kept it together".

(Student focus group 3)

"Nurses are really good sources of information. They know the routines, medications and normal practices far better than we do (or even) the junior doctors".

(Student focus group 3)

"Sometimes it's the other health care professionals that are more receptive to students. I (went) to some physio sessions and that's where I learned most of my orthopaedic examinations...you find a person who takes you under their wing...boosts your confidence as well as pushing you to learn...it all comes back to that whole communication thing and forming relationships".

(Student focus group 1)

\section{Discussion}

The study was limited by resource and the inaccessibility of students and supervisors due to the wide geographical range of teaching units used for clinical teaching at the University of Glasgow. The purposive sample of supervisors had to be augmented by approaching individual tutors and a convenience sample of students had to be used. Despite the recruitment problems, and not using the same moderator for all three focus groups, meaningful data were considered to have been produced. These data can be used to inform an observational study of clinical settings, which would strengthen the validity of the findings.

Good students were viewed, by both supervisors and students, as being enthusiastic and motivated. They were considered to be proactive in seeking out relevant learning experiences and were observed by supervisors as being visible in the wards. This is an important quality where students are expected to be active in managing their own learning. They appear confident, knowledgeable, able to prioritise information, flexible and competent in basic clinical skills by the time of graduation. The need to be proactive, while being adaptive, however is another example of medical education's blending of incompatible norms $[10,11]$. Good students are considered by supervisors and students to be compassionate, able to communicate with, and be respectful of, patients and colleagues. They were also observed to be genuine when interacting with patients and colleagues. They are not afraid to seek help when necessary and are aware learning is a lifelong commitment. They are felt to have a sense of vocation. Poor students on the other hand were noted, by both supervisors and students, to attend less frequently and when they do, tend not to participate to the same extent. They appear anxious and scared of patients' illnesses and seem afraid of taking responsibility. They appear not to be as interested, although some supervisors reflected this was not the case at their medical school selection interviews. They were viewed by supervisors as making less effort, being less knowledgeable, less able to prioritise information and having less sense of their future roles. Supervisors felt they also interacted less well with ward team members. Validation of identity by patients and members of communities of practice was found to promote professional inclusivity [12]. However, students who show unwillingness to participate, or are on the margins may have their identities' disconfirmed and may be deprived of learning opportunities [13]. Non-participation among students may, however, be a way of resisting the "normalizing technologies" of professional socialization [14]. This should be considered and explored by teachers.

Our findings could be used for clinical students' formative assessments and help evaluate their effectiveness as self-directed learners in clinical settings. They could help flag up concerning behaviours at an early stage enabling appropriate intervention. They could also be useful for tutor training.

The findings on what characterises a good teacher are consistent with other studies and reviews $[5-7,15,16]$. They exhibited the characteristics highlighted in the literature on effective role models; high standards of clinical competence, excellence in clinical teaching skills and humanistic personal qualities [17]. The importance 
of non-cognitive characteristics such as inter-personal skills and relationship building was particularly emphasised by both students and supervisors. Our findings are also consistent with Dornan et al's study [18] that effective clinical teachers simultaneously support and challenge students in ways that builds competence and confidence. Effective teachers are those who stretch students, using a repertoire of teaching and learning approaches, but who do not take students too far outside their Vygotskyian Zones of Proximal Development (ZPD). To be effective, teachers need to take into account individual differences among students, and the communicative nature of the learning process through which students learn and develop $[19,20]$. Good teachers were noted to promote student participation in ward communities of practice. The best teachers were considered to exhibit similar characteristics in their clinical work and were considered genuine when interacting with patients and colleagues. This reflects Goffman's [21] distinction between convincing and unconvincing performances.

Teachers who were felt to be poor were found to push students beyond their ZPDs, having little awareness of students' learning needs and individual characteristics, with a tendency to humiliate students when they exhibited lack of knowledge or skills. This has the effect of marginalising and de-motivating students. It reflects a disconnection between what students were taught in the classroom about professionalism and what they experience in the ward setting [21]. Teachers exhibiting these forms of behaviour are considered by students to be unprofessional and are recognised as negative role models. A particular characteristic of these teachers is a perceived lack of interpersonal skills resulting in poor relationships with students, patients and colleagues. The abuse of power exercised by such teachers can have negative consequences for student learning.

Our findings could again be used in tutor training and as a basis for formative assessment of tutors by both colleagues and students.

Other members of the clinical communities of practice can be effective teachers, mentors and role models. Students' participation in the communities of practice is pivotal. Students are aware of the need to foster relationships with their teachers, other doctors and members of the ward team, which is recognised as an important investment in their learning. Student learning in clinical settings should be seen as a collective responsibility.

\section{Conclusions}

- Supervisors and students see good clinical students as being proactive in their learning; an important quality where students are expected to be active in managing their own learning.
- Good clinical students seem to share similar characteristics with good clinical teachers

- Student learning in clinical settings is a collective responsibility.

- A teacher's enthusiasm and non-cognitive abilities are as important as their cognitive abilities.

- Our findings could be used in tutor training and for formative assessment of both clinical students and teachers. This may promote early recognition and intervention when problems arise.

\section{Competing interests}

The authors declare that they have no competing interests.

\section{Authors' contributions}

JG devised the study, was involved in its design, implementation, data analysis and wrote the initial and final drafts and agrees to be accountable for all aspects of the work. AD was involved in the design, implementation, data analysis and commented on the drafts. He has given final approval of the version to be submitted and agrees to be accountable for all aspects of the work. AG was involved in the design, implementation, data analysis and commented on the drafts. She has given final approval of the version to be submitted and agrees to be accountable for all aspects of the work. PC was involved in the design, implementation, data analysis and commented on the drafts. He has given final approval of the version to be submitted and agrees to be accountable for all aspects of the work. JM was involved in the design of the study, supervised its implementation and analysis and commented on the drafts. She has given final approval of the version to be submitted and agrees to be accountable for all aspects of the work. All authors read and approved the final manuscript.

\section{Authors' information}

John Goldie was lead researcher in the evaluation of ethics learning in Glasgow University's curriculum for 10 years. For the last 6 years he has been lead researcher on projects investigating the delivery of professionalism teaching and the formation of medical students' professional identity. Al Dowie is the Senior University Teacher at Glasgow University Medical School with responsibility for the Ethics and Law curriculum theme. He chairs the community of practice for ethics theme leaders across the five Scottish medical schools on behalf of the Scottish Deans Medical Education Group. His empirical research brings qualitative methods to the domain of professional learning in clinical settings.

Anne Goldie is the manager of the Tom Allan Counselling Service Glasgow. She sits on the advisory group of the Scottish Counselling Research Network. She has a particular interest in exploring new qualitative methodology. Phil Cotton is an academic general practitioner. He was Professor of Learning and Teaching in the Undergraduate Medical School at the University of Glasgow. He is now Principal of the College of Medicine and Health Sciences, University of Rwanda.

Jill Morrison is an academic general practitioner. She is currently the Dean for Learning and Teaching in the College of Medical, Veterinary and Life Sciences at the University of Glasgow. She was previously Head of the Undergraduate Medical School.

\section{Funding}

The study was internally funded.

\section{Author details}

${ }^{1}$ Glasgow University Medical School, Glasgow, Scotland, UK. ${ }^{2}$ Tom Allan Centre, Glasgow, Scotland, UK. ${ }^{3}$ College of Medicine and Health Sciences, University of Rwanda, Kigali, Rwanda. ${ }^{4}$ College of Medical, Veterinary and Life Sciences, University of Glasgow, Glasgow, Scotland, UK. ${ }^{5}$ Academic Unit of General Practice and Primary Care, University of Glasgow, 1 Horselethill Road, Glasgow G12 9LX, Scotland, UK.

Received: 26 June 2014 Accepted: 18 February 2015

Published online: 10 March 2015 


\section{References}

1. Karakitsiou DE, Markou A, Kyriakou P, Pieri M, Abuaita M, Bourousis E, et al. The good student is more than a listener - The $12+1$ roles of the medical student. Med Teach. 2012;34(1):e1-8.

2. Harden RM, Crosby J. AMEE Guide No 20: The good teacher is more than a lecturer - the twelve roles of the teacher. Med Teach. 2000;22(4):334-47.

3. General Medical Council. Recommendations on Undergraduate Medical Education. London UK: GMC; 2002.

4. General Medical Council. Good Medical Practice. London: GMC; 2013.

5. Sutkin G, Wagner E, Harris I, Schiffer R. What Makes a Good Clinical Teacher in Medicine? A Review of the Literature. Acad Med. 2008:83:452-66.

6. Bannister SL, Raszka Jr WW, Maloney CG. What makes a great clinical teacher in pediatrics? Lessons learned from the literature. Pediatrics. 2010;125:86.

7. Alsultan M. What makes an effective clinical trainer? Saudi J Kidney Dis Transplant. 2011;22(6):1229-35.

8. Morgan DL. Focus groups as qualitative research. 2nd ed. Newbury Park, CA: Sage; 1997.

9. Ritchie J, Spencer L. Qualitative data analysis for applied policy research. In: Bryman A, Burgess R, editors. Analysing qualitative data. London: Routledge; 1994.

10. Merton RK, Reader GG, Kendall PL. The student-physician. Cambridge: Harvard University Press; 1957.

11. Griffin MA, Neal A, Parker SK. A new model of work role performance: Positive behavior in uncertain and interdependent contexts. Acad Manage J. 2007;50:327-47.

12. Weaver R, Peters K, Koch J, Wilson I. "Part of the team": professional identity and social exclusivity in medical students. Med Educ. 2011;45(12):1220-9.

13. Lyon P. A model of teaching and learning in the operating room. Med Educ. 2004;38(12):1278-87.

14. Jaye C, Egan T, Parker S. "Do as I say not as I do": Medical education and Foucault's normalizing technologies of self. Anthropol Med. 2006;13(2):141-55

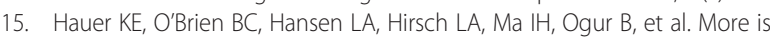
better: students describe successful and unsuccessful experiences differently in brief and longitudinal relationships. Acad Med. 2012;87:1389-96.

16. Stalmeijer RE, Dolmans DH, Snellen-Balendong $H$, van Santen-Huefft M, Wolfhagen $\mathrm{IH}$, Scherpbler AJ. Clinical teaching based on the principles of cognitive apprenticeship: Views of experienced clinical teachers. Acad Med. 2013;88:861-5

17. Passi V, Johnson S, Peile E, Wright S, Hafferty F, Johnson N. Doctor role modeling in medical education: BEME Guide No 27. Med Teach. 2013:35:e1422-36.

18. Dornan T, Boshulzen H, King N, Schreiper A. Experience-based learning: a model linking the processes and outcomes of medical students' workplace learning. Med Teach. 2007:41:84-91

19. Wink J, Putney LG. A vision of Vygotsky. Toronto, ON: Allyn and Bacon; 2001.

20. Duvivier RJ, van Dalen J, van der Vleuten CP, Scherpbier AJ. Teacher perceptions of desired qualities, competencies and strategies for clinical skills teachers. Med Teach. 2009:31:634-41.

21. Goffman E. The Presentation of Self in Everyday Life. Hammondsworth: Penguin Books; 1990.

\section{Submit your next manuscript to BioMed Central and take full advantage of:}

- Convenient online submission

- Thorough peer review

- No space constraints or color figure charges

- Immediate publication on acceptance

- Inclusion in PubMed, CAS, Scopus and Google Scholar

- Research which is freely available for redistribution 